\title{
Antral Resection versus Antral Preservation during Laparoscopic Sleeve Gastrectomy: Does Outcome Differ?
}

\author{
Ahmed Elhoofy, ${ }^{1}$ Wael Omar, ${ }^{2}$ Mohamed Mahmoud El Sayed Ibrahim ${ }^{3}$ \\ 1,3 Department of General Surgery, Ain Shams University, Egypt \\ ${ }^{2}$ Department of General Surgery, Helwan University, Egypt
}

Background: The surgical technique of sleeve gastrectomy has not been fully standardized and, therefore, there are issues to be solved. Resection of the antrum is one of these debatable issues.

Aim: The study aims at assessing the difference in long and short term weight loss between both antral resection laparoscopic sleeve gastrectomy \& antral preservation laparoscopic sleeve gastrectomy.

Patients and methods: Is a prospective randomized control study including 100 patients with BMI exceeding 35, fifty of them will undergo antral preservation in laparoscopic sleeve gastrectomy (group A), and the other fifty patients will undergo antral resection in laparoscopic sleeve gastrectomy (group B).

Results: Weight loss and BMI reduction after 6 months in the antral resection group were more than the antral preservation group with mean weight $92.25 \mathrm{~kg}$ in antral resection group compared to $99.46 \mathrm{~kg}$ in antral preservation group and mean BMI 34.48 in antral resection group compared to 39.29 in antral preservation group. Also weight loss and BMI reduction after 12 months in the antral resection group were more than the antral preservation group with mean weight $71.60 \mathrm{~kg}$ in antral resection group compared to $77.20 \mathrm{~kg}$ in antral preservation group and mean BMI 26.41 in antral resection group compared to 30.71 in antral preservation group.

Conclusion: Antral resection in LSG safely potentiates the restrictive effect achieved and may result in greater and better maintained weight loss.

Key words: Laparoscopic sleeve gastrectomy, Obesity, Antral preservation, Antral resection.

\section{Introduction}

Laparoscopic sleeve gastrectomy (LSG) is an effective operation for severe obesity, with comparable shortterm outcomes to Roux-en-Y gastric bypass (RYGB) for weight loss and diabetes resolution. ${ }^{1}$

Laparoscopic sleeve gastrectomy (LSG) was first described as the initial step of a two-staged bariatric procedure for high-risk patients. ${ }^{2,3}$

In subsequent years, LSG has been described as a stand-alone bariatric procedure, and it is currently one of the bariatric procedures most rapidly growing in popularity. This is because of promising results in terms of excess weight loss and the resolution of comorbidities. ${ }^{4,5}$

However, LSG is not as straightforward as one might think, and the technique has not yet been standardized. There is an overall tendency toward more restriction of the final sleeve by using a smaller bougie and leaving a shorter antrum. ${ }^{6}$

One aspect of controversy is the extent to which the antrum is excised. When fashioning the sleeve the staple line may be commenced close to the pylorus or at some distance away, resulting in more or less antral excision. Practice between surgeons is highly variable. ${ }^{1}$ The objective of this systematic review is to compare weight loss outcomes between antral-sparing (AP) and antral-resecting (AR) LSG for obesity.

\section{Patient and methods}

This a prospective randomize control study held in El Demerdash hospital, Ain Shams university and Badr university hospital, Helwan University between November 2015 till December 2017 including one hundred patients with BMI exceeding 35, fifty of them underwent antral resection in laparoscopic sleeve gastrectomy, and the other fifty patients underwent antral preservation in laparoscopic sleeve gastrectomy. An informed consent was taken from all patients who accepted to participate in our study. All the patients in this study were randomly divided into two groups taking care that both groups were age matched. A unique computer generated randomization schedule was used. This consisted of alternating blocks, and was faithfully reproduced into sealed, ordered envelopes and kept in the operating theatre. The patients were divided into two groups. Group A: Antral preservation group included 50 patients where stapling started $6 \mathrm{~cm}$ from the pylorus while Group B: Antral resection group included the other 50 patients where stapling started 2 $\mathrm{cm}$ from the pylorus. 
All patients included in the study were subjected to:

\section{Pre-operative:}

History taking:

- Age \& sex.

- Weight \& BMI.

- Dietary habits.

- History of previous operations (type, time, place, complications).

\section{Examination:}

A. General: Full general examination must be done, focusing on:

- Cardio-vascular fitness.

- Respiratory fitness.

B. Local: Full abdominal examination focused on:

- Scars of previous operations.

- Abdominal wall hernias.

\section{Investigations:}

Laboratory:

- General pre-operative investigations for all the patients included: full blood picture; prothrombin time, partial thromboplastin time; liver function tests: albumin; liver enzymes (AST, ALT); kidney function tests: (serum urea, serum creatinine) and electrolytes (sodium and potassium).

- Thyroid profile included: Free T3 \& free T4 \& TSH.

- Fasting blood sugar and HBA1c.

- Cardio-vascular investigations: All patients had ECG, CXR; while some had ECHO if they had cardiac troubles, and respiratory function tests and arterial blood gases if they had respiratory troubles as sleep apnea.

- Radiological: All patients had pre-operative pelviabdominal ultrasound to show any intra-abdominal and pelvic organs pathology as well as assessment of liver size.

Intra-operative:

Our technique was the laparoscopic five puncture technique focusing on

- Operative time.

- Anatomy and Operative findings.

- Conversion to open surgery.

\section{Postoperative:}

Follow up to detect the difference between the 2 groups focusing on:

- Early Postoperative complications( leakage, bleeding).

- Postoperative hospital stay.

- Long term complications (stenosis, GERD, ulceration).

- Long term weight loss (6 and 12 months postoperative).

\section{Inclusion criteria:}

- Body mass index exceeding 35.

- Age: More than 18 years and less than 60years

- Gender: Both sexes.

- Fit for surgery.

- Motivated patients to be a part of the study.

\section{Exclusion criteria:}

- Contraindication to laparoscopy.

- Patients with hypothyroid state \& on replacement therapy.

- Patient refusal or mentally retarded.

- Psychiatric illness.

\section{Data collection:}

Data was collected from patient records and medical files. Statistical presentation and analysis of the present study was conducted, using the mean, standard Deviation, student t-test, and chi-square test by SPSS V.20.

\section{Results}

100 patients were included in our randomized study (86 female patients and 14 male patients), and were divided to 2 groups; antral preservation group (group A) and antral resection group (group B) as shown in Table 1.

Table 1: Showing no significant demographic differences between both groups as regard age and sex

\begin{tabular}{|c|c|c|c|c|c|c|}
\hline & \multirow[t]{2}{*}{ No. $=\mathbf{5 0}$} & $\begin{array}{c}\text { Antral } \\
\text { Preservation }\end{array}$ & $\begin{array}{c}\text { Antral } \\
\text { Resection }\end{array}$ & \multirow[t]{2}{*}{ Test value } & \multirow[t]{2}{*}{ P-value } & \multirow[t]{2}{*}{ Sig. } \\
\hline & & No. $=\mathbf{5 0}$ & & & & \\
\hline \multirow{2}{*}{ Age } & Mean \pm SD & $34.44 \pm 7.45$ & $33.50 \pm 9.88$ & \multirow{2}{*}{0.537} & \multirow{2}{*}{0.592} & \multirow{2}{*}{ NS } \\
\hline & Range & $22-46$ & $20-54$ & & & \\
\hline \multirow{2}{*}{ Sex } & Female & $40(80.0 \%)$ & $46(92.0 \%)$ & \multirow{2}{*}{2.990} & \multirow{2}{*}{0.084} & \multirow{2}{*}{ NS } \\
\hline & Male & $10(20.0 \%)$ & $4(8.0 \%)$ & & & \\
\hline
\end{tabular}

P-value $>0.05$ : Non-significant; P-value $<0.05$ : Significant; P-value $<0.01$ : Highly significant; NA: Not applicable.

*: Chi-square test; $\bullet$ : Independent t-test. 
As regard the preoperative measurements, there were no significant variations between both groups as regard preoperative weight, height and BMI with mean preoperative weight $122 \mathrm{~kg}$ in antral preservation group and $127 \mathrm{~kg}$ in antral resection group, mean preoperative BMI $48.3 \%$ in antral preservation group and $47.06 \%$ in antral resection group.

Patients with comorbidities as DM and HTN were not included in our study for the aim of justifying both groups results without underlying diseases.
As regard the early post-operative complications, there were no bleeding or leakage reported in our 2 groups. In this study we compared the weight loss in both groups after 6 months. Our study showed significant increase in weight loss and BMI reduction after 6 months in the antral resection group more than the antral preservation group with mean weight $92.25 \mathrm{~kg}$ in antral resection group compared to $99.46 \mathrm{~kg}$ in antral preservation group. As regard BMI; our study showed high statistically significant value as the mean BMI in the antral resection group was 34.48 compared to 39.29 in the antral preservation group.

Table 2: Shows the variations in weight loss and BMI reduction after 6 months between both groups

\begin{tabular}{|c|c|c|c|c|c|c|}
\hline \multicolumn{2}{|l|}{ No. $=\mathbf{5 0}$} & \multirow{2}{*}{$\begin{array}{c}\text { Antral } \\
\text { Preservation } \\
\text { No. }=\mathbf{5 0}\end{array}$} & \multirow[t]{2}{*}{$\begin{array}{c}\text { Antral } \\
\text { Resection }\end{array}$} & \multirow[t]{2}{*}{ Test value• } & \multirow[t]{2}{*}{ P-value } & \multirow[t]{2}{*}{ Sig. } \\
\hline & & & & & & \\
\hline \multirow{2}{*}{ Weight after 6 months (kg) } & Mean \pm SD & $99.46 \pm 16.59$ & $92.25 \pm 17.10$ & \multirow{2}{*}{2.1399} & \multirow{2}{*}{0.042} & \multirow{2}{*}{$S$} \\
\hline & Range & $76-140$ & $65-117$ & & & \\
\hline \multirow{2}{*}{ BMI after 6 months (\%) } & Mean \pm SD & $39.29 \pm 6.91$ & $34.48 \pm 5.48$ & \multirow{2}{*}{3.858} & \multirow{2}{*}{0.000} & \multirow{2}{*}{ HS } \\
\hline & Range & $28.2-53.2$ & $24-43.5$ & & & \\
\hline
\end{tabular}

P-value > 0.05: Non-significant; P-value < 0.05: Significant; P-value < 0.01: Highly significant; NA: Not applicable.

$\bullet$ : Independent t-test

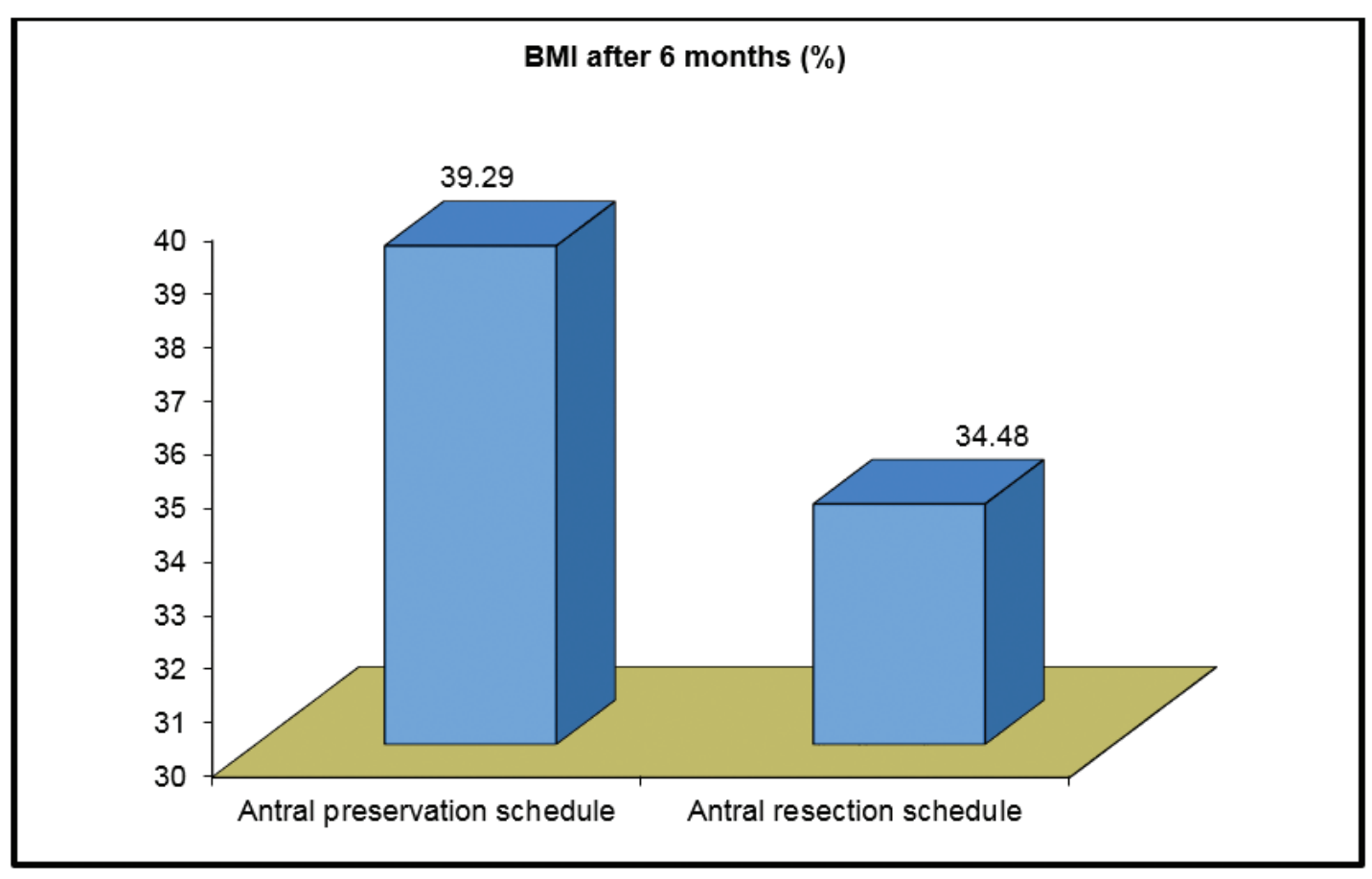

Graph 1: Variations in weight loss and BMI reduction after 6 months between both groups.

Our study showed also significant increase in weight loss and BMI reduction after 12 months in the antral resection group more than the antral preservation group with mean weight $71.60 \mathrm{~kg}$ in antral resection group compared to $77.20 \mathrm{~kg}$ in antral preservation group. As regard BMI, our study showed high statistically significant value as the mean BMI in antral resection group was 26.41 compared to 30.71 in antral preservation group. 
Table 3: Shows the variations in weight loss and BMI reduction after 12 months between both groups

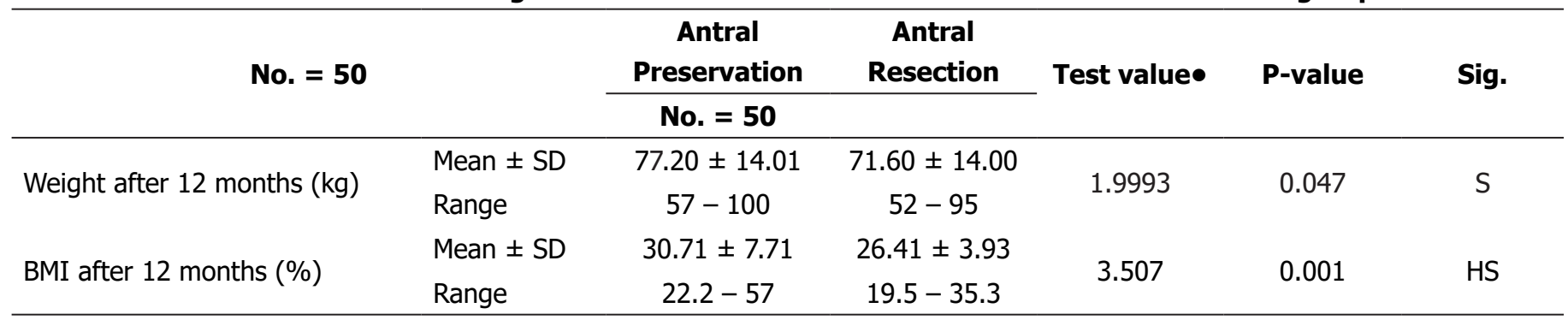

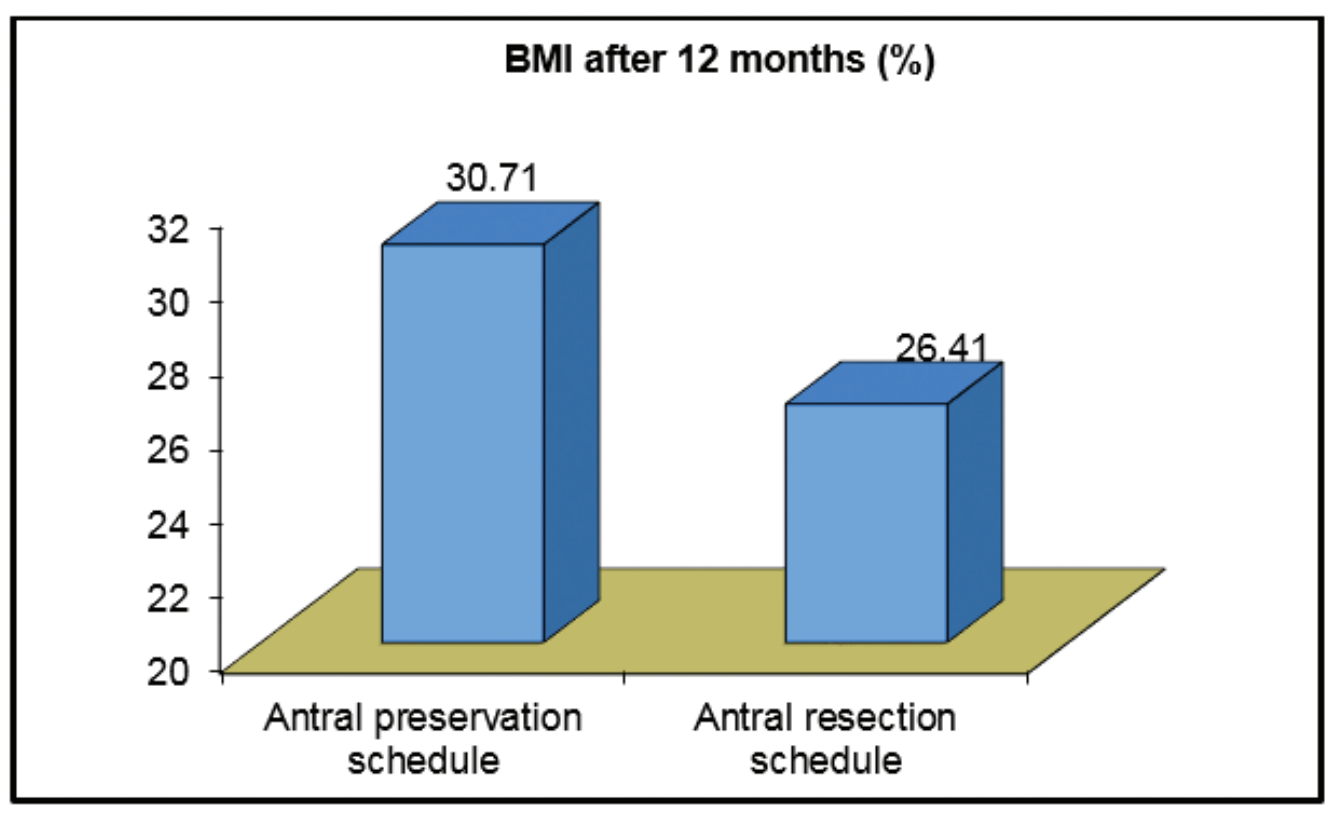

Graph 2: Variations in weight loss and BMI reduction after 12 months between both groups.

In our study operative time was shorter in the antral preservation group than in the antral resection group.

Although our study showed non-significant variations between both groups as regard incidence of GERD and developing vomiting, 3 patients developed GERD and 10 patients developed vomiting in the antral resection group compared to 6 patients who developed vomiting but not GERD in the antral preservation group.

Hospital stay was 1 day for all patients in both groups and no conversion to open sleeve gastrectomy was done in any patient in both groups.

Table 4: Shows the variations in operation time, late postoperative complication (GERD, ulceration and vomiting), hospital stay and conversion to open surgery between both groups

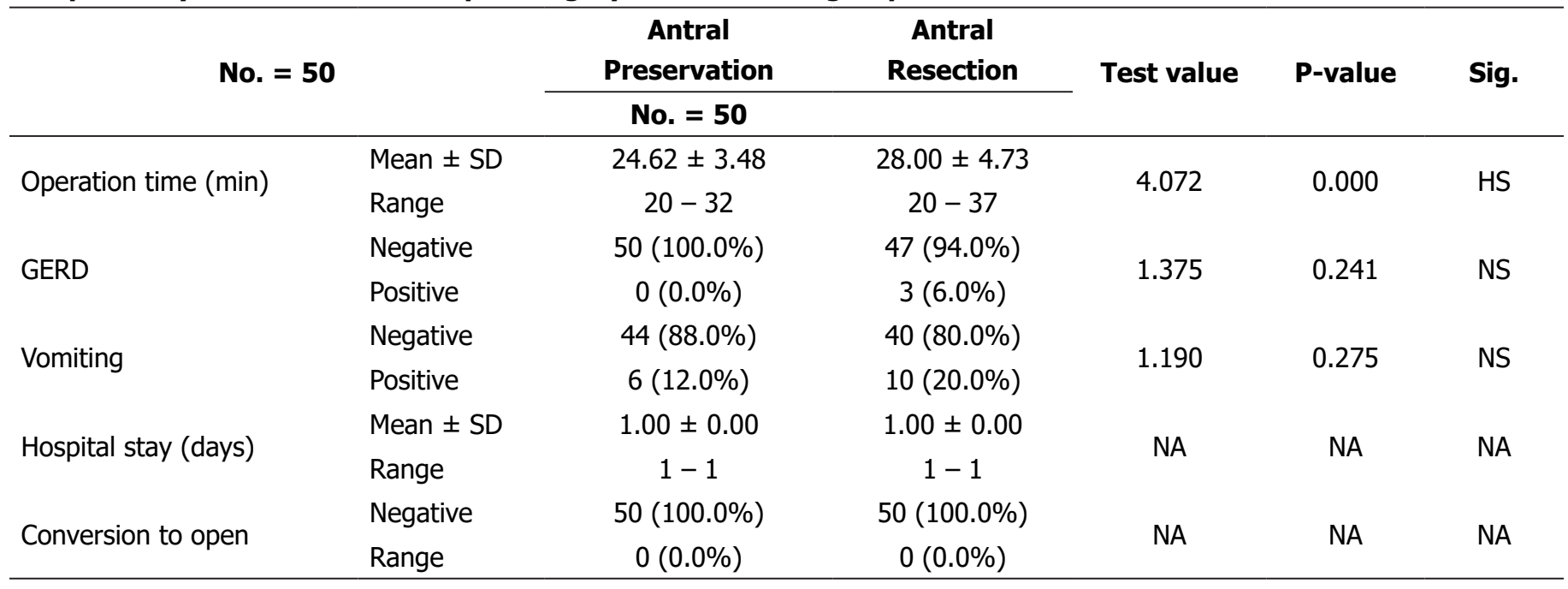




\section{Discussion}

Sleeve gastrectomy is primarily considered a restrictive type of bariatric surgery, where surgical technique plays a major role in the resulting and maintained weight loss. The ideal restriction creates a narrow gastric tube without a large antral pouch, leaving a gastric capacity of no more than $80 \mathrm{ml}^{7}$

Although LSG is generally associated with good weight loss, some patients experience poor primary weight loss and a significant proportion of patients demonstrate weight regain (which tends to occur following a plateau of maximal weight-loss at about 12-18 months postsurgery. ${ }^{23,24}$ Both of these adverse events are clearly clinically important, and there is much interest in operative approaches to prevent them. ${ }^{8,9}$

The degree of antral resection is a controversial issue in LSG. Some surgeons prefer antral resection and beginning stapling $2 \mathrm{~cm}$ from pylorus. ${ }^{4,10,11}$

Whereas others start $6 \mathrm{~cm}$ from the pylorus, there by preserving the gastric antrum. . $^{10,12-17}$

Supporters for antral resection claim that stapling within $2 \mathrm{~cm}$ of the pylorus adds more restriction and may contribute to better weight loss. ${ }^{4}$

The mechanism of action of the sleeve gastrectomy is believed to involve a combination of gastric restriction, hormonal effects, and changes in gastric motility and eating habits. ${ }^{18}$

Despite this clearly multifactorial mechanism, the size of the restriction performed is the most significant factor for weight reduction and maintenance. Moreover, the antrum tends to enlarge with time and the increased volume may contribute to weight regain. ${ }^{19}$

Mognol et al. ${ }^{11}$ and Baltasar et al. ${ }^{4}$ Began the division approximately $2 \mathrm{~cm}$ from the pylorus; they argue that since LSG is a purely restrictive procedure, the restriction should be more aggressive than when it is a part of another procedure such as a duodenal switch.

On the other hand, those with antral preservation see that doing so preserves contractile function, promoting gastric emptying and thus reducing intraluminal pressure and potentially decreasing leakage.6,10,12

One of the main differences between AR and AP that could theoretically influence weight loss and weight regain is sleeve volume: In AR procedures the fashioned sleeve would be expected to have a smaller volume a finding which has been confirmed on volumetric CT scanning. ${ }^{20}$ Few studies have examined the impact of sleeve volume on weight loss, but evidence suggests that while initial sleeve volume is not correlated with early weight loss, ${ }^{21,22}$ beyond two years the formation of a narrower sleeve intraoperatively may be associated with significantly improved weight loss. ${ }^{23}$
Studies that have looked at the effect of pyloric antral resection on weight loss have shown conflicting results. Jacobs et al. showed no statistically significant difference in the \%EWL following creation of a 4versus $7-\mathrm{cm}$ antral pouch. ${ }^{24}$ In contrast, analysis of data from the Spanish national registry revealed that resection closer to the pylorus resulted in better weight loss during the first and second postoperative years. ${ }^{25}$ Our study showed that a more radical antral resection resulted in significantly better weight loss in the first postoperative year.

It should be noted however that the volume of sleeves, and also the relative differences in volume between AR and AP sleeves, does change with time from surgery. ${ }^{20}$ Longer-term follow up in trials of patients undergoing AP and AR sleeve gastrectomy is indicated to determine whether the weight loss advantage with AR continues to increase with time and what correlation, if any, this has with sleeve volume.

The other concern regarding radical antral resection is its effect on reflux symptoms. LSG's effect on gastroesophageal reflux (GERD) is controversial. LSG may lessen reflux by reducing intra-abdominal pressure (by way of decreasing intra-abdominal fat) and reducing acid production by decreasing gastric tissue. ${ }^{26-27}$ Postoperative reflux may be attributed to technical issues; for example, partial resection of the sling fibers of the LES, which can produce a hypotensive LES, has been suggested to result in GERD. ${ }^{26} \mathrm{~A}$ lack of gastric compliance, severely restricted gastric capacity with an intact pylorus, and impaired gastric emptying have also been suggested to predispose patients to reflux during the first postoperative period. ${ }^{28-30}$ Whether antral resection is associated with the development of GERD is still controversial. Nocca et al. ${ }^{31}$ performed resection at $10 \mathrm{~cm}$ from the pylorus and suggested that preservation of the antrum reduces the symptoms of reflux. However, Daes et al. ${ }^{32}$ reported a very low incidence of postoperative GERD despite $3-\mathrm{cm}$ antral resection. Our study showed no significant increase in the incidence of GERD symptoms in the antral resection group. This can be explained by the faster emptying mechanism previously suggested by some authors. However, further studies comparing gastric emptying are needed.

\section{Conclusion}

LSG is a safe and effective bariatric procedure. The performance of radical antral resection safely potentiates the restrictive effect achieved by LSG and may result in greater and better maintained weight loss without increasing the complication rate. Long-term follow-up data and larger studies are needed to confirm these results, particularly in super-obese patients.

The authors listed above certify that they have no affiliations with or involvement in any organization or entity with any financial interest (such as honoraria; educational grants; participation in speakers' bureaus; membership, employment, consultancies, 
stock ownership, or other equity interest; and expert testimony or patent-licensing arrangements), or nonfinancial interest (such as personal or professional relationships, affiliations, knowledge or beliefs) in the subject matter or materials discussed in this manuscript.

\section{References}

1. McGlone ER, Gupta AK, Reddy M, Khan OA: Antral resection versus antral preservation during laparoscopic sleeve gastrectomy for severe obesity: Systematic review and meta-analysis. Surg Obes Relat Dis. 2018; 14(6): 857-864.

2. Ren $\mathrm{CJ}$, Patterson $\mathrm{E}$, Gagner M: Early results of laparoscopic biliopancreatic diversion with duodenal switch: A case series of 40 consecutive patients. Obes Surg. 2000; 10(6): 514-523.

3. Regan JP, Inabnet $W B$, Gagner $M$, et al: Early experience with two stage laparoscopic Roux-en-Y gastric bypass as an alternative in the super-super obese patient. Obes Surg. 2003; 13(6): 861-864.

4. Baltasar A, Serra C, Perez N, Bou R, Bengochea M, Ferri L: Laparoscopic sleeve gastrectomy: A multipurpose bariatric operation. Obes Surg. 2005; 15: $1124-1128$.

5. Lee CM, Cirangle PT, Jossart GH: Vertical gastrectomy for morbid obesity in 216 patients: report of two-year results. Surg Endosc. 2007; 21(10): 1810-1816.

6. Michalsky D, Dvorak P, Belacek J, et al: Radical resection of the pyloric antrum and its effect on gastric emptying after sleeve gastrectomy. Obes Surg. 2013; 23(4): 567-573.

7. Braghetto I, Korn O, Valladares $\mathrm{H}$, et al: Laparoscopic sleeve gastrectomy: Surgical technique, indications and clinical results. Obes Surg. 2007; 17(11): 14421450.

8. Maciejewski ML, Arterburn $\mathrm{DE}$, Van Scoyoc $\mathrm{L}$ et al: Bariatric surgery and long-term durability of weight loss. JAMA Surg. 2016; 151(11): 1046-1055.

9. Lauti M, Lemanu D, Zeng ISL, Su'a B, Hill AG, MacCormick AD: Definition determines weight regain outcomes after sleeve gastrectomy. Surg Obes Relat Dis. 2017; 13(7): 1123-1129.

10. Givon-Madhala O, Spector R, Wasserberg N, et al: Technical aspects of laparoscopic sleeve gastrectomy in 25 morbidly obese patients. Obes Surg. 2007; 17: 722-727.

11. Mognol P, Chosidow C, Marmuse JP: Laparoscopic sleeve gastrectomy as an initial bariatric operation for high-risk patients: Initial results in 10 patients. Obes Surg. 2005; 15: 1030-1033.
12. Cottam D, Qureshi FG, Mattar G, et al: Laparoscopic sleeve gastrectomy as an initial weight loss procedure for high-risk patients with morbid obesity. Surg Endosc. 2006; 20: 859-863.

13. Silecchia G, Boru C, Pecchia A, et al: Effectiveness of laparoscopic sleeve gastrectomy (first stage of biliopancreatic diversion with duodenal switch) onco-morbidities in super-obese high-risk patients. Obes Surg. 2006; 16: 1138-1144.

14. Bernante $P$, Foletto $M$, Busetto $L$, et al: Feasibility of laparoscopic sleeve gastrectomy as a revision procedure for prior laparoscopic gastric banding. Obes Surg. 2006; 16: 1327-1330.

15. Roa PA, Kaidar-Person O, Pinto D, Cho M, Szomstein $\mathrm{S}$, Rosenthal RJ: Laparoscopic sleeve gastrectomy as treatment for morbid obesity: technique and short-term outcome. Obes Surg. 2006; 16: 13231326.

16. Langer FB, Bohdjalian A, Felberbauer FX, et al: Does gastric dilation limit the success of sleeve gastrectomy as a sole operation for morbid obesity? Obes Surg. 2006; 16: 166-671.

17. Sánchez-Santos R, Masdevall C, Baltasar A, et al: Short and mid-term outcomes of sleeve gastrectomy for morbid obesity: The experience of the Spanish National Registry. Obes Surg. 2009; 19: 1203-1210.

18. Papailou J, Albanopoulos K, Toutouzas KG, Tsigris C, Nikiteas N, Zografos G: Morbid obesity and sleeve gastrectomy: how does it work? Obes Surg. 2010; 20: 1448-1455.

19. Braghetto I, Korn O, Valladares H: Laparoscopic sleeve gastrectomy: Surgical technique, indications and clinical results. Obes Surg. 2007; 17: 14421450.

20. Vives M, Molina A, Danús M et al: Analysis of gastric physiology after laparoscopic sleeve gastrectomy (LSG) with or without antral preservation in relation to metabolic response: A randomised study. Obes Surg. 2017; 20(7): 964-969.

21. Pawanindra L, Vindal A, Midha M, Nagpal $P$, Manchanda A, Chander J: Early postoperative weight loss after laparoscopic sleeve gastrectomy correlates with the volume of the excised stomach and not with that of the sleeve! Preliminary data from a multi-detector computed tomography-based study. Surg Endosc. 2015; 29(10): 2921-2927.

22. Pomerri $F$, Foletto $M$, Allegro $G$, Bernante $P$, Prevedello L, Muzzio PC: Laparoscopic sleeve gastrectomy-radiological assessment of fundus size and sleeve voiding. Obes Surg. 2011; 21(7): 858-863. 
23. Weiner RA, Weiner $S$, Pomhoff I, Jacobi C, Makarewicz W, Weigand G: Laparoscopic sleeve gastrectomy--influence of sleeve size and resected gastric volume. Obes Surg. 2007; 17(10): 12971305.

24. Jacobs M, Bisland W, Gomez E, et al: Laparoscopic sleeve gastrectomy: A retrospective review of 1- and 2-year results. Surg Endosc. 2010; 24(4): 781-785.

25. Sánchez-santos $R$, Masdevall C, Baltasar A, et al: Short- and midterm outcomes of sleeve gastrectomy for morbid obesity: the experience of the Spanish National Registry. Obes Surg. 2009; 19(9): 1203-1210.

26. Braghetto, Italo, Enrique Lanzarini, Owen Korn, Héctor Valladares, Juan Carlos Molina, and Ana Henriquez: "Manometric changes of the lower esophageal sphincter after sleeve gastrectomy in obese patients. Obesity surgery. 2010; 20: 357-362.

27. Hamoui N, Anthone GJ, Kaufman HS, et al: Sleeve gastrectomy in the high-risk patient. Obes Surg. 2006; 16(11): 1445-1459.
28. Lazoura O, Zacharoulis D, Triantafyllidis G, et al: Symptoms of gastroesophageal reflux following laparoscopic sleeve gastrectomy are related to the final shape of the sleeve as depicted by radiology. Obes Surg. 2011; 21(3): 295-299.

29. Melissas J, Koukouraki S, Askoxylakis J, et al: Sleeve gastrectomy: A restrictive procedure? Obes Surg. 2007; 17(1): 57-62.

30. Tai CM, Huang CK, Lee YC, et al: Increase in gastroesophageal reflux disease symptoms and erosive esophagitis 1 year after laparoscopic sleeve gastrectomy among obese adults. Surg Endosc. 2013; 27(4): 1260-1266.

31. Nocca D, Krawczykowsky D, Bomans B, et al: A prospective multicenter study of 163 sleeve gastrectomies: Results at 1 and 2 years. Obes Surg. 2008; 18(5): 560-565.

32. Daes J, JimenezME, Said N, et al: Laparoscopic sleeve gastrectomy: Symptoms of gastroesophageal reflux can be reduced by changes in surgical technique. Obes Surg. 2012; 22(12): 1874-1879. 